\title{
DISSECAÇÃO SIMBÓLICA DO CORPO: OS ESTUDOS ANATÔMICOS DE FRANÇOIS DELSARTE E SUAS REVERBERAÇÕES NA PERCEPÇÃO DO MOVIMENTO, A PARTIR DE UM RECORTE SOBRE A DANÇA MODERNA AMERICANA
}

\author{
Robson Lourenço \\ Professor nos Cursos de Graduação em Dança e Teatro da Universidade Anhembi-Morumbi \\ Doutorando em Artes da Cena pela Universidade Estadual de Campinas \\ Email: lourencorobson@uol.com.br \\ Julia Ziviani Vitiello \\ Professora Titular do Departamento de Artes do Corpo do Instituto de Artes da Universidade Estadual \\ de Campinas \\ Doutora em Educação pela Universidade Estadual de Campinas \\ Email: ziviani.julia@gmail.com
}

Este artigo reflete sobre as percepções desenvolvidos pelo artista e pedagogo francês François Delsarte (1811-1871), a partir do campo do conhecimento da anatomia. Delsarte foi responsável por um amplo estudo e análise do movimento do corpo humano no contexto europeu do século XIX, quando se propõe a desenvolver uma sistematização que refletiria sobre a simbologia do gesto e também uma investigação da expressividade através do corpo. Sob a perspectiva dos saberes da anatomia e também da transmissão de conhecimento, o artigo desenvolve reflexões a partir de trechos de textos de Genèvieve Stebbins (1857-1937) e cartas de James Steele Morrison MacKaye (1842-1894). Por fim desenvolve comentários a partir do estudo de trechos da obra "Every Little Movement", de Ted Shawn (1963), quando apresenta e discute possíveis cruzamentos de como a trajetória e a pedagogia de François Delsarte estariam presentes na reflexão escrita, na produção artística e na pesquisa de corpo de Shawn.

Palavras-chave

Dança.Transmissão. Gesto. Movimento. Anatomia.
This article ponders over French artist and educator François Delsarte's (1811-1871) perceptions on the field of anatomical knowledge. Delsarte was responsible for a broad study and the analysis of human body movements within the European context of the XIX century, when he sought to develop both a system that could be imprinted on the symbology of gestures and an investigation of expressiveness using the body. When considering anatomical knowledge and the transmission of knowledge, this article develops impressions from Genèvieve Stebbins' (1857-1937) excerpts and James Steele Morrison MacKaye's (1842-1894) letters. Finally, it presents comments on excerpts from Ted Shawn's book Every Little Movement (1963), wherein he introduces and discusses possible intersections with François Delsarte's trajectory and education and how they would be present in Ted Shawn's own written reflections, artistic production and bodily research.

Keywords

Dance. Transmission. Gesture. Movement. Anatomy. 
Este artigo reflete sobre as percepções desenvolvidas pelo artista François Delsarte, a partir do campo do conhecimento da anatomia e levanta hipóteses de como tais saberes foram desenvolvidos posteriormente por Geneviève Stebbins e James Steele Morrison MacKaye em suas obras e cartas. Através de comentários sobre trechos da obra de Ted Shawn (1963), apresenta e discute possíveis cruzamentos entre a trajetória de François Delsarte e como sua pedagogia esteve presente na pesquisa de corpo de Shawn, que reverberaria em aspectos de sua produção artística e também em sua reflexão escrita. Esta investigação partiu dos estudos realizados dentro da pesquisa de doutorado realizada entre 2013 e 2017, no Programa de Pós-Graduação em Artes da Cena da Universidade Estadual de Campinas (UNICAMP'1).

Antes de iniciarmos a reflexão deste artigo, apresentaremos alguns aspectos da biografia de François Delsarte que são relevantes para a compreensão da construção da sua percepção sobre corpo e movimento ao longo de sua carreira. Tais pontos de sua vida reverberariam na pedagogia de Delsartee servirão como base para a posterior reflexão de como os conhecimentos anatômicos do artista francês ecoariam em seu futuro sistema de pensamento.

François Delsarte iniciou sua formação artística na Escola Real de Música e Declamação de Paris em 1826². Três anos após o ingres-

1 A investigação de doutorado de onde partiu a reflexão para este artigo intitula-se "Passado-Presente da percepção de si: escavando a preparação do artista da dança através de narrativas anatómicas" e será defendida em julho/2017.

2 Delsarte nasceu na cidade de Solesmes em 1811, um vilarejo noroeste de Paris. Segundo Delamousne (1893), Delsarte mudou-se para Paris com sua mãe e seu irmão mais velho após a separação de seus pais e, na capital francesa, Delsarte ingressaria na Escola Real de Música e Declamação de Paris em 1826. so na escola real, o artista francês começaria a perder sua voz gradativamente e, segundo Ted Shawn (1963), esta alteração no aparelho fonador de Delsarte ocorreu devido aos métodos para treinamentos vocais utilizados dentro do Conservatório. Mesmo com a perda de voz, a pesquisadora americana Nancy Lee Chalfa Ruyter (1999) declara que Delsarte trabalhou como ator em teatros da época logo após a sua saída daquela instituição. Naqueles ambientes teatrais, o artista francês apresentava-se apenas esporadicamente e Ruyter levanta a hipótese de que no período de ócio, Delsarte começou a refletir suas teorias iniciais de expressão artística. Posteriormente, Delsarte retirou-se da carreira como ator e apresentou-se regularmente como cantor em seus próprios concertos, de 1839 a 1866. Além disto, desenvolve uma carreira como pedagogo e ministra cursos de expressão vocal em conjunto com o estudo do movimento, na sala de sua casa.

Para o desenvolvimento do seu sistema de reflexão sobre o corpo, Delsarte acumulou por muitos anos fatos através da observação empírica. Shawn (1963) cita uma situação em que o artista francês viajou uma grande distância, com o intuito de observar o recolhimento de corpos mortos em um desabamento de uma mina e descreve que Delsarte foi até lá "com o intuito de estudar, como cientista desapaixonado, as atitudes, gestos, tom de voz e maneira de falar daqueles que esperavam na superfície" (Shawn, 1963, p. 16, tradução nossa). 
Figura 1: Divisão do Tronco e Crânio desenhado à mão por François Delsarte.

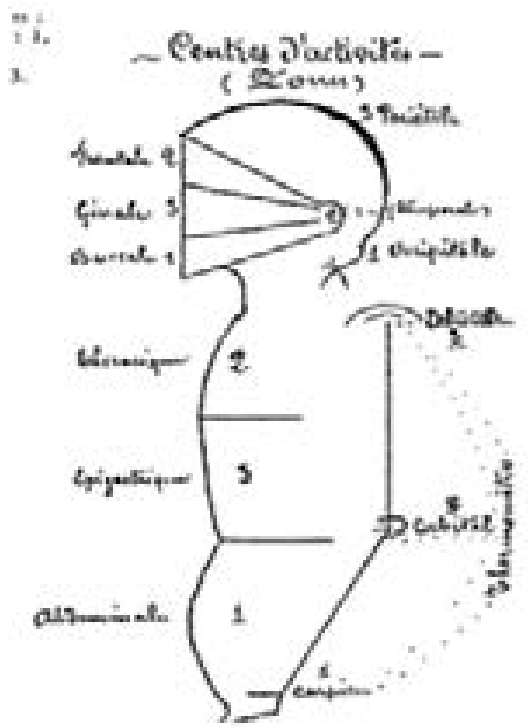

Fonte: Porte, 2012.

A partir de suas observações, François Delsarte começaria a desenvolver um sistema de pensamento sobre o corpo, que assumiria um interesse central em sua pesquisa ao longo de sua carreira como pedagogo. Para Delsarte (2012) o "corpo é um pequeno mundo que porta em si os acontecimentos da inteligência. $O$ corpo é um alfabeto enciclopédico e é a chave para levar nosso mundo natural à união com as harmonias criadas" (Delsarte apud Porte, 2012, p. 102).

A fé cristã de François Delsarte seria um dos motes de desenvolvimento do seu futuro alfabeto de movimento, pois para o artista francês o ser humano estaria em contato com a natureza divina ao integrar em si as suas três dimensões, que seriam estabelecidas através das relações iniciais entre a vida, a alma e o espírito. François Delsarte nomearia estas relações como Princípio da Trindade e tal fundamento seria desdobrado em reflexões sobre o movimento, quando "Toda verdade deve corresponder a este organismo, o corpo, para conseguir nos alcançar e por consequência a verdade deve se mostrar à nós triplamente" (Delsarte apud Porte, 2012, p. 103).

Além do Princípio da Trindade, há outro fundamento refletido por Delsarte dentro de sua teoria, quando propõe que "cada função espiritual corresponderia a uma função do corpo e cada uma das funções do corpo responderia a um ato do espírito" (Porte, 2012, p. 259, tradução nossa). Este trânsito entre cada parte do corpo e sua função espiritual, Delsarte denominaria como Lei de Correspondência. Para Ruyter (1999), a Lei de Correspondência no sistema de Delsarte desenvolveria relações entre o corpo e outros aspectos cultivados pelo ser humano, ao interligar o "tangível e o intangível, o que é de dentro e o de fora, movimento e significado" (Ruyter, 1999, p. 76, tradução nossa). No entanto, como seria desenvolvido o sistema de pensamento de François Delsarte através do corpo?

A integração trinitária e o princípio de correspondência inter-relacionavam-se entre si a partir da filosofia do pensamento de Delsarte. Para desenvolver uma explanação da integração dos princípios da Trindade em conjunto com a Lei de Correspondência, apresentamos ao lado um desenho à mão feito pelo artista francês da cabeça e do tronco humano. Nesta ilustração é possível exemplificar como seria classificada cada porção do dorso segundo Delsarte. Gostaríamos de chamar a atenção do leitor para a tríade da parte frontal do tronco, representada na ilustração com seus respectivos números.

$\mathrm{Na}$ figura apresentada, o número um está localizado na parte inferior do desenho e seria a porção abdominal; a zona de número dois seria a parte superior e próxima ao crânio (nomeada por Delsarte como torácica) e, finalmente, a divisão de número três seria a porção 
epigástrica e estaria localizada na porção central do corpo. Na relação entre os conhecimentos desenvolvidos por Delsarte e a leitura de seus conhecimentos por Ted Shawn, o artista americano aprofunda a relação com a tríade mental, moral e física do tronco de Delsarte, quando Shawn reflete:

a parte superior do peito é mental, sede da honra, da consciência e se relaciona com os pulmões; que é a porção espiritual (para que a respiração e o espírito tenham como raiz a palavra em nascente); o meio do dorso é a zona emocional, sede dos estados de espírito e se relaciona com o coração e o plexo solar; [...] o tronco inferior, a porção abdominal, é a zona física e vital do dorso, com o estômago, intestinos e os órgãos sexuais serem a sede dos apetites. (Shawn, 1963, p. 38, tradução nossa)

O conhecimento trinitário desenvolvido por François Delsartee posteriormente apresentado por Ted Shawn transita entre o ato de dividir incessantemente o corpo em parcelas simbólicas e paralelamente integrar tal conhecimento às nomenclaturas anatômicas. Delsarte aos poucos revela uma riqueza de detalhes sobre possíveis subdivisões do corpo, como as porções epigástricas ou torácicas do dorso.

Uma das chaves para Delsarte desenvolver seu alfabeto de leitura sobre as diferentes partes do corpo baseou-se na relação que o artista desenvolveu com o campo de conhecimento da anatomia. Ted Shawn (1963) afirma que Delsarte frequentou um curso completo de anatomia dentro da Faculdade de Medicina de Paris, quando dissecou corpos e entrou em contato direto com os saberes do interior do corpo humano através do estudo de cadáveres.

\section{François Delsarte (Delsarte apud Porte,}

2012 , 64-66) relata que conheceu os ambientes de dissecação (teatros anatômicos) aos quinze anos de idade e este período coincide com o momento que iniciou seus estudos no Conservatório. Um primo o teria convidado a visitar o anfiteatro da Faculdade de Medicina em Paris e naquele recinto Delsarte entraria em contato direto com as dissecações do corpo humano.

O escritor Francis A. Durivage (1893) afirma que Delsarte "devotou cinco anos a estudar anatomia e fisiologia, para obter um perfeito conhecimento de todos os músculos, seus usos e capacidades - um conhecimento que utilizou com sucesso memorável" (DURIVAGE in DELAUSMONE et al. 1893, p. 589, tradução nossa). Aos quinze anos de idade, o que teria motivado Delsarte a conhecer tais ambientes de dissecação? O que o contato com aquele local de estudo da anatomia traria para seu futuro sistema de pensamento como artista e pedagogo? Segundo o relato do próprio François Delsarte, a curiosidade o teria impulsionado àquele local, quando descreve que foi atraído:

pelo divertimento e também em parte pelo prazer. Era como uma festa que não esperava a hora de chegar. Mas ao estar ali, naquele lugar frio e sombrio como um sepulcro, me sentia sufocado com a ação dos gases nocivos emitidos a partir daquele lugar infectado, me vi na presença daqueles montes de corpos mutilados pelo bisturi, desfigurados pela decadência e devorados em parte por ratos e vermes. Debaixo das mesas havia despojos horríveis, como tonéis de lixo humano jogados de modo desprezível. Membros e pedaços de carte cortadas foram reduzidos à condição de lama infectada e meu coração saltou em todas as direções, quando fui tomado por uma repulsão indescritível ... $\mathrm{O}$ que? Eu disse a mim mesmo, essas massas informes e em putrefação vi- 
veram! Eles pensaram! Eles amaram, e quem iria acreditar no horror e no nojo que inspiram, mas eles foram amados, acariciados e até mesmo adorados! (Delsarte apud Porte, 2012, p. 64, tradução nossa)

Nas primeiras décadas de 1800, Delsarte entraria em contato direto com o fenômeno do estudo dos cadáveres e o artista apresenta a etapa primal do conhecimento anatômico, antes do discernimento dissecado de músculos e adiante ainda da separação da carne que revela ossos ensanguentados. Somente após o esquartejamento minucioso de cada parcela do corpo humano, que o conhecimento da anatomia é posteriormente organizado e apresentado em livros, tratados, aulas ou palestras. Assim, dentro dos locais de dissecação frequentados por Delsarte, um outro tema começa a ser levantado pelo artista: a morte, quando François Delsarte refletiria o que estaria por detrás daqueles corpos dissecados:

Os mortos, e tudo o que seria atraente sob seu ponto de vista, não podiam sorrir para mim com a condição de estarem dissecados ou, pelo menos, esfolados. Eu queria, como as crianças que quebram suas bonecas, ver o que está atrás da morte, e pareceu-me que, sob a mutilação que um bisturi faz ao corpo e eu ia até lá para ver como a vida aparece e como surgiria o verbo por trás daquele enigma. (Delsarte apud Porte, 2012, p. 64, tradução nossa)

A curiosidade do artista francês pendulou entre o corte provocado pela dissecação do bisturi e futuras indagações, quando Delsarte começa a procurar no corpo dos cadáveres algum sinal de como reconhecer uma morte recente. Através dos corpos espalhados pelo chão, o artista observa:
No entanto, no meio de tantos objetos repulsivos [...] Eu já estava procurando por um sinal claro de como poderia ser reconhecida uma morte recente. Sobre este assunto eu rapidamente explorei e observei todas as partes do corpo de vários cadáveres que permaneciam intactos. Eu estava procurando por uma característica comum e um sinal invariavelmente afetava a todos, quando as mãos me deram a indicação e responderam amplamente à minha pergunta. Notei que os polegares de todos esses cadáveres tinham uma atitude singular; fiquei impressionado com o movimento de adução daqueles dedos que nem o dia nem o sono tinham oferecido à minha visão. Foi uma iluminação. Eu tentei ter mais certeza ainda da minha descoberta e olhei no balde que continham braços separados do tronco; e as mãos ainda eram afetadas por esta disposição do tendão flexor, com as mãos traçando este sinal. (Delsarte apud Porte, p. 66, tradução nossa)

No trecho acima, François Delsarte levanta a hipótese de que os cadáveres tinham os polegares aduzidos em direção à palma da mão. Tal observação dos dedos nos corpos retaIhados instigou Delsarte a procurar se tal fato também ocorreria em pessoas que estivessem em uma etapa próxima à morte, quando o artista francês solicitou a um dos estudantes da Faculdade de Medicina que o levasse ao leito de um paciente que estivesse em estado terminal. Postado ao lado da cama de uma pessoa em seus instantes finais de vida, Delsarte testemunha:

Constatei que os polegares do moribundo se retraíam de modo quase imperceptível, mas quando a batalha final se aproximou e diante dos esforços supremos que fez para agarrar-se à vida que the escapava, vi todos os dedos moverem-se convulsivamente em direção à palma da mão, que esconderam os polegares e avançaram em direção ao centro de convergência 
da mão. Após a crise da morte, os dedos voltaram para a posição normal, mas a retração dos polegares persistia, conforme observações anteriores. A presença e o encaminhamento deste fenômeno em um moribundo foram confirmados em inúmeras verificações que fiz posteriormente. (Delsarte apud Porte, 2012, p. 67, tradução nossa)

A minúcia de como Delsarte transportou o fenômeno de observação das mãos de um corpo cadavérico para um ser humano moribundo apresenta a habilidade do artista francês em desenvolver relações que beiram a metafísica, pois transpassou aquilo que percebeu dentro dos ambientes de dissecação para uma pessoa em seu leito de morte. O limiar entre vida e morte observado por Delsarte estava encharcado pelo contexto de estudo da anatomia das primeiras décadas de 1800 , quando os saberes da dissecação abririam caminhos para que o campo de conhecimento da anatomia auxiliasse eventuais diagnósticos em autópsias e incrementasse o campo de conhecimento da patologia, que é a especialidade médica que estuda as doenças e as alterações que levam o organismo ao falecimento.

O início do século XIX é um período quando se iniciam as pesquisas que relacionariam o histórico particular de cada paciente que viesse a falecer à investigação minuciosa da causa de sua morte, pois durante a autópsia de pessoas recém-falecidas, a dissecação buscaria em cada tecido e órgão o motivo da morte daquele indivíduo. Segundo o filósofo francês Michel Foucault, naquele período houve uma diminuição do tempo de latência entre a morte de um indivíduo e uma eventual autópsia, o que "permitiu fazer coincidir, ou quase, o último momento do tempo patológico e o primeiro do tempo cadavérico" (Foucault, 2011, p. 156). Citado por Michel Foucault, um dos primeiros histologistas e patologistas franceses, o médico Marie François Xavier Bichat reflete:

Durante 20 anos, noite e dia, se tomarão notas, ao leito dos doentes, sobre as afecções do coração, dos pulmões e da víscera gástrica e o resultado será apenas confusão nos sintomas, que, a nada se vinculando, oferecerão uma série de fenômenos incoerentes. Abram alguns cadáveres: logo verão desaparecer a obscuridade que apenas a observação não pudera dissipar. (Bichat apud Foucault, 2011, p. 162)

A dissecação de cadáveres recém-falecidos buscava distinguir o que seria inerente ao cadáver e o que pertenceria à doença que levou ao eventual falecimento do indivíduo. De acordo com Foucault, naquele momento:
A vida, a doença e a morte constituem [...] uma trindade técnica e conceitu- al. A velha continuidade das obses- sões milenares que colocava, na vida, a ameaça da doença e, na doença, a presença aproximada da morte é rom- pida: em seu lugar, se articula uma fi- gura triangular, de que o cume supe- rior é definido pela morte. É do alto da morte que se podem ver e analisar as dependências orgânicas e as sequên- cias patológicas. (Foucault, 2011, p. 159)

O corpo morto começa a se distinguir como espaço de construção dos saberes sobre eventuais patologias de um indivíduo e a dissecação durante a autópsia começa a discernir tecidos infectados por doenças daqueles que estariam sãos, de modo a identificar com precisão qual seria a porção do corpo que teria levado ao óbito uma determinada pessoa. Sobre tais dissecações, Foucault reflete:

Em lugar de permanecer o que tinha sido durante tanto tempo, noite em que a vida se apaga e em que a pró- 
pria doença se confunde, ela é dotada, de agora em diante, do grande poder de iluminação que domina e desvela tanto o espaço do organismo quanto o espaço da doença [...] O privilégio de sua atemporalidade, que é sem dúvida tão velho quanto a consciência de sua iminência, torna-se, pela primeira vez, instrumento técnico que permite a apreensão da verdade da vida e da natureza de seu mal. A morte é a grande analista que mostra as conexões, desdobrando-as, e explode as maravilhas da gênese no rigor da decomposição. (Ibidem, p. 159-60)

Embebido pelos entrelaçamentos decorrentes das relações entre os campos de conhecimento da anatomia e da patologia nas primeiras décadas do século XIX, Delsarte caminha entre cadáveres, disseca corpos em decomposição e também observa pessoas em estado terminal na Faculdade de Medicina de Paris, quando indaga se não haveria a possibilidade de contemplar em corpos vivos a abdução ou adução dos polegares de pessoas em situações cotidianas.

Delsarte faria suas observações em transeuntes dos Jardim das Tulherias, quando se misturaria às crianças acompanhadas por suas mães e babás. Naquele ambiente, Delsarte poderia observar pessoas em movimento e procurar pistas sobre suas hipóteses, quando relata:

Então eu vi babás distraídas e indiferentes às crianças que acompanhavam. Em suas mãos, o polegar era invariavelmente perto dos dedos e mostravam também uma adução semelhante àquela que se manifesta na morte. Em outras babás mais afetuosas, os dedos das mãos que seguravam as crianças dirigiam-se de forma significativa e seria possível perceber o polegar se estender excentricamente. Mas essa abertura do polegar para fora adquire proporções ainda mais espantosas entre as mães que saiam com seus filhos (Delsarte apud Porte, 2012, p. 70, tradução nossa)

Os dedos das mãos observados por Delsarte abririam a possibilidade para uma miríade de estudos, quando indaga: "o critério da morte não se constituiria um termômetro para a vida?" (Delsarte apud Porte, 2012, p. 67). A partir da observação das mãos, Delsarte desenvolveria a possibilidade de experimentação do movimento apartir da proximidade e distanciamento de partes do corpo em relação ao centro do indivíduo. Esse estudo que o levaria a definir os movimentos comoexcêntricos, normais e concêntricos.

Construímos a metáfora do pêndulo entre morte e vida para associá-la às possíveis relações existentes entre os movimentos excêntricos e concêntricos desenvolvidos por Delsarte. Para o artista francês,os movimentos excêntricos representariam a vida e seriam aqueles que partiriam sua ação do centro de uma região do corpo em direção à sua periferia. Já os concêntricos poderiam estar associados à morte ou ao espirito e seriam aqueles cuja origem partiriam das extremidades em direção ao centro de uma porção corporal. Na trajetória pendular entre vida e morte estariam os movimentos normais, que seria ao mesmo tempo ponto de passagem e também de partida entre os movimentos concêntricos e excêntricos do corpo humano.

Para exemplificar como era desenvolvido o sistema de pensamento de Delsarte, apresentamos uma representação do movimento das mãos segundo seu sistema de pensamento. Tal ilustração foi retirada da obra "Every Little Movement", de Ted Shawn (1963) e foram sobrepostas legendas em português para auxiliar a compreensão e reflexão posterior de tais 
gestos a partir da classificação realizada por Delsarte:.

Partindo de suas observações anatômicas e das relações entre morte e vida, Delsarte tranferiria tais apontamentos para o estudo do movimento, quando desenvolveria um estudo minucioso do gesto em aulas ministradas na sala de sua casa.Os alunos compareciam àqueles encontros e gradualmente experienciavam diferentes possibilidades do estudo do movimento. Delsarte refletiria que a prática e o estudo constante levariam o aluno de seu método a ser um "observador silencioso dos fenômenos que o cercam e se manifestam dentro de si mesmo" (Delsarte apud Porte, 2012, p. 260). A partir do que foi experimentado por discípulosna sala da casa de Delsarte, que posteriormente seu conhecimento foi difundido.

Figura 2: Atitudes das mãos segundo François Delsarte (com sobreposição de legendas em português).

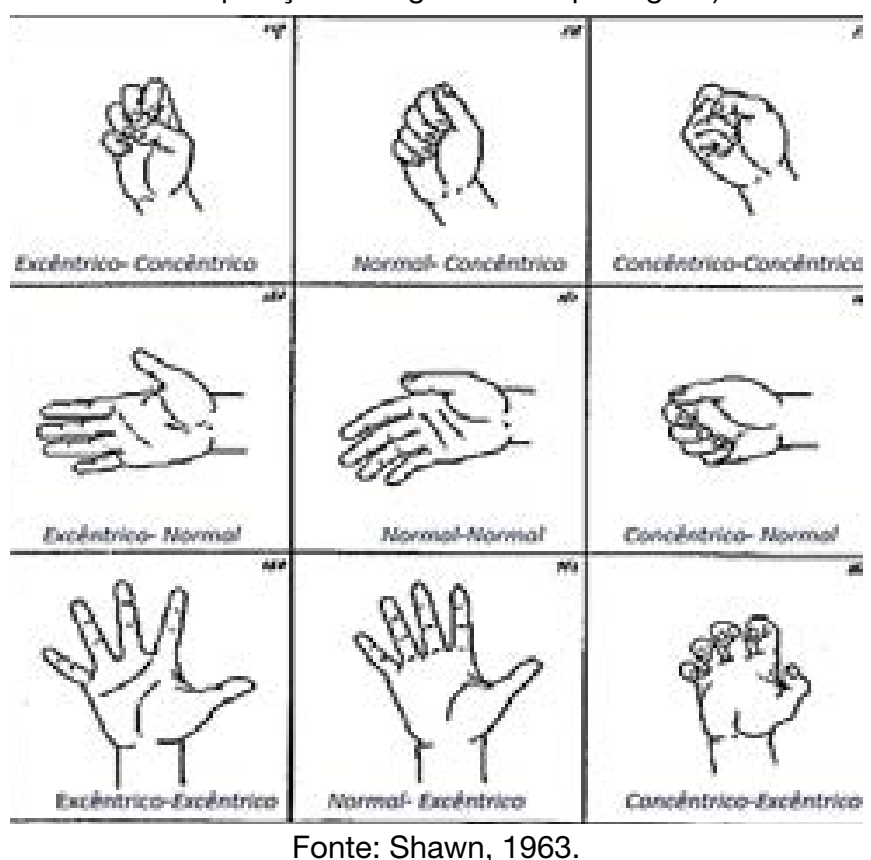

O desafio ao refletir sobre o legado de conhecimentos de François Delsarte é desenvolver uma triagem do que foi realmente refletido pelo pesquisador francês e o que foi atribuído a ele por seus seguidores. Ao ponderar sobre a rede de transmissão de saberes desenvolvida a partir de Delsarte, o pesquisador Franck Waille (2011) expressa que há a:

ambição de reconstruir uma prática viva e que foi difundida essencialmente de modo oral, através de uma transmissão direta realizada via mestre-discípulo, mas vestígios dessa transmissão permanecem na forma de documentos escritos (em diversas publicações de seus alunos) e em fontes que poderíamos chamar de semi orais; que seriam anotações feitas por seus alunos durante suas aulas, além de notas feitas pelo próprio Delsarte. (Waille, 2011, p. 130, tradução nossa)

A partir da reflexão de Waille, algumas perguntas poderiam ser levantadas para esta reflexão: como os movimentos excêntricos, concêntricos e normais seriam posteriormente desenvolvidos por seus discípulos? Como tais movimentos reverberariam mais tarde no movimento característico da dança, sob o olhar e estudo de Ted Shawn? Os saberes de François Delsarte ultrapassariam as fronteiras francesas por meio de um dos discípulos diretos do pesquisador: o ator e diretor teatral americano James Morrison Steele MacKaye, que estudou com Delsarte em seu estúdio parisiense, no biênio 1869/70. O período de aprendizagem com o mestre francês foi interrompido em virtude da guerra franco-prussiana. MacKaye retornaria à sua terra natal com a intenção de em seguida trazer François Delsarte para o território americano, mas tal intento foi frustrado com a morte de François Delsarte em julho de 1871. Com o inesperado falecimento do artista e pedagogo francês, a difusão de seu pensamento em território americano foi realizada diretamente por Steele MacKaye através de palestras-demonstrações. 
Há alguns vestígios de que a disseminação dos conhecimentos de François Delsarte feita por MacKaye nos Estados Unidos foi de uma maneira diferenciada daquela que apreendera na sala do artista francês. Sobre este processo de alteração de conhecimentos, Nancy Ruyter (1999) apresenta uma carta de Mac Kaye, onde o artista apresenta o caminho de organização dos conhecimentos de François Delsarte, quando relata:

Antes de Delsarte e eu nos separarmos, eu havia lançado os alicerces de todo o meu sistema [...]. Enquanto estava com Delsarte, lecionei para muitos alunos esta série de gestos aplicando meu próprio sistema de treinamento para eles com resultados que despertaram o maior espanto e um entusiasmo profundo em Delsarte. Ele percebeu que eu poderia compreender e aplicar tudo que me ensinou - E que eu também era criativo e reflexivo. Me reconheceu como seguidor do seu trabalho artístico e me nomeou como seu único discípulo - ao me aceitar como colaborador e sucessor. (Mackaye apud Ruyter, 1999, p. 19, tradução nossa)

Entre os procedimentos desenvolvidos por MacKaye, Ruyter (1999) levanta os exercícios de relaxamento ou decomposição, que teriam o objetivo de "liberar todos os agentes expressivos do corpo [...] com o intuito de suprimir a tendência automática de ação que existam nas fibras musculares" (Ruyter, 1999, p. 85, tradução nossa) ${ }^{3}$. Mas como seriam os exercícios de decomposição propostos por MacKaye para liberar a musculatura durante um procedimento corporal?

Como MacKaye não escreveu um tratado de

3 Este é um trecho de uma das anotações de Steele Mackaye presente em outro arquivo consultado por Ruyter, que estaria nos arquivos Delsarte, na Universidade Estadual de Louisiana, caixa 2, pasta 51 (Ruyter, 1999, p. 88). seu sistema de procedimentos, encontramos vestígios de seu pensamento na obra de uma de suas discípulas: Geneviève Stebbins, que apresenta algumas pistas de como o estudo do relaxamento do corpo seria desenvolvido através dos exercícios propostos inicialmente por Steele MacKaye. Para Stebbins, o primeiro elemento a ser percebido dentro deste tipo de exercício seria a identificação das articulações, para que as "correntes de força nervosa possam escoar através delas, como um jorro de água que atravessa um canal, sem ser barrado por obstáculos" (Stebbins, 1887, p. 11, tradução nossa).

Após identificar as articulações do corpo, Stebbins proporia $o$ ato de ceder as musculaturasque envolveriam o encontro dos ossos e direcionaria os feixes musculares para chão. Apresentamos uma sequência de procedimentos apresentados por Stebbins (1887), que visavam o relaxamento do corpo:

1 - Ceda os dedos a partir das articulações como se estivessem sem vida. A força vital deve parar nas articulações. 2 - Deixe as mãos caírem a partir do pulso, como se estivessem mortas; balance-as para frente e para trás, para cima e para baixo, para ambos os lados e também balance as mãos em rotação.

3 - Deixe cair o antebraço a partir dos cotovelos, como se estivessem sem vida. Os sacuda levemente. A força vital se transferirá para os cotovelos.

4 - Levante os braços acima da cabeça, faça os exercícios de decomposição, como indicado anteriormente, removendo a força de cada parte dos braços. Eles ão como um peso morto. Os braços ainda ficarão pendurados e relaxando em partes a partir dos ombros, mova o corpo como um suporte em movimentos circulares. Os braços deverão balançar como se fossem pesos mortos; agora troque e balance o corpo para frente e para trás, com os joelhos dobrados. Os braços descreverão círculos a partir de suas bases, 
quando deverão estar relaxados.

5 - Deixe cair a cabeça para um dos lados, relaxando o movimento. Ela gradualmente fará uma trajetória em meio círculo, movendo-se a partir de seu próprio peso, como quando olhamos para uma pessoa que tomba a cabeça quando adormecida. Deixe cair a cabeça para trás, decompondo o movimento.

6 - Deixe cair o torso para os lados, decompondo o movimento, começando pela cabeça. A cabeça trará o ombro e, gradualmente, sem esforço, o dorso como um todo cairá. Faça isto primeiramente para um lado, depois para o outro

7 - Levante o pé do chão, agitando-o como você fez com a mão. É meIhor você se sentar para realizar este exercício. Esteja certo que o pé cederá a partir do tornozelo, decompondo o movimento.

8 - Relaxe o movimento a partir da parte baixa da perna, sacudindo esta parte a partir dos joelhos.

9 - Com o peso do corpo na parte de trás da perna, dobre os joelhos em conjunto com o dorso para frente. A cabeça deverá ceder para trás. 10 Mantenha a atenção na parte de trás da perna; e o corpo cederá em direção ao chão.

Deixe as pálpebras caírem como se estivesse indo dormir.

11 - Deixe a mandíbula cair e perceba seu peso, relaxando o movimento. (Stebbins, 1887, p. 12-4, tradução nossa)

Isolar cada parte do corpo ou ceder a musculatura através movimentos das articulações são atos corporais muito sutis e são apresentados de modo minucioso por Geneviève Stebbins. Em outra de suas obras, Stebbins (1913) encoraja o leitor a perceber o corpo e prepará-lo para os exercícios de decomposição:

Deite-se no chão, relaxe o mais completamente possível, de modo que o corpo fique praticamente suave e inerte, como se não fizesse parte de você. A ideia mental é conjugar uma perfeita e calma consciência de qualquer par- te do corpo durante um exercício, de modo que seja feito de maneira independente e elevada da consciência. Tudo isto deve ser acompanhado de respiração rítmica e caso o ambiente que o contorne seja bonito, a mente deve procurar uma relação agradável e sonhadora com o seu entorno. Caso contrário, feche os olhos e imagine o mar e o céu, um jardim de rosas ou uma colina, um gramado ou um arbusto florido. (Stebbins, 1913, 34, tradução nossa)

Segundo o pesquisador francês Georges Vigarello (2016), os procedimentos de relaxamento apresentados por Stebbins conduziriam a um estado diferenciado de percepção daqueles indivíduos que os praticassem, pois aose relaxarem procurariam a "lentidão calculada de cada movimento, a preocupação com uma concentração precisa do gesto" (Vigarello, 2016, p. 288). A autora Susan Foster (2011) aprofunda a reflexão levantada por Vigarello e reflete que as ações de relaxamento propostas por Stebbins desenvolveriam ainda "uma forte conexão com a gravidade e uma percepção do movimento tanto em sua tensão como em sua tridimensionalidade" (Foster, 2011, p. 109, tradução nossa).

Steele MacKaye e Geneviève Stebbins disseminaram o conhecimento de François Delsarte dentro do movimento nomeado como "Delsartismo Americano". No entanto, este momento de disseminação dos saberes de Delsarte não se concentrava apenas nestes dois indivíduos e delineou-se como um fenômeno ainda mais amplo. Para ilustrar a expansão das ideias de François Delsarte no continente americano no final do século XIX, a pesquisadora Nancy Ruyter (1999) apresenta alguns números desta disseminação. Entre 1870 e 1890, a autora afirma que havia de cerca de quatrocentos professores e artistas nos Estados Unidos, que se 
autoidentificavam como "Delsartistas"4, pois alegavam que seus conhecimentos eram baseados nos princípios de François Delsarte e que tal saber era um componente significativo em seu modo de percepção do movimento do corpo.

Segundo Ruyter (1999), estes professores e artistas atuavam em todos os 38 estados que formavam a confederação americana naquele período, com uma concentração maior no nordeste do país, em especial nas cidades de Nova lorque e Boston. O nome de François Delsartetrans formou-se em um fenômeno que transpassou as salas de estudo voz, de atuação e de expressão e chegou a transformar-se em marca de produtos. Shawn (1963) afirma que o nome "Delsarte" estampou espartilhos, cosméticos, roupões e seu nome chegou a ser utilizado até mesmo em próteses de madeira para amputados 5 . Tais produtos eram associados ao nome de François Delsarte em virtude do conforto que proporcionavam àqueles que os utilizavam.

No esteio do movimento de disseminação dos conhecimentos de Delsarte no território americano, que Ted Shawn ${ }^{6}$ entra em contato

4 A autora Nancy Lee Chalfa Ruyter (1999) nomeia os professores e artistas como "delsarteanteachers" ou "delsartean performers". No momento da tradução optou-se pelo termo "delsartista" para denominar os indivíduos que ministravam aulas segundo os princípios de Delsarte.

5 Segundo a historiadora Annie Suquet (2005), a quantidade de amputados após a Guerra de Secessão Americana foi imensa e os fabricantes preocupavam-se em oferecer próteses que fossem mais articuladas e com alavancas que favorecessem a mobilidade e a fluidez do movimento (Shawn in Suquet, 2005, p. 224).

6 Nascido na cidade de Denver em 1891, Ted Shawn seria um dos responsáveis pela elaboração das primeiras raízes da chamada dança moderna americana nas primeiras décadas de 1900. Em conjunto com sua esposa Ruth Saint-Denis, Shawn fundaria uma escola de dança, cujo nome era uma ligação contraída de seus sobrenomes: a Denishawn School, onde ambos os artistas nutririam o terreno para a reflexão corporal de uma geração de futuros criadores de coreografias e técnicas da dança moderna americana nas primeiras décadas com o pensamento do artista francês na passagem do século XIX para o XX.A partir das relações entre movimentos excêntricos e concêntricos apresentados por Delsarte até o estudo das possíveis tensões e os relaxamentos propostos por Stebbins e MacKaye, foi possível a Shawn começar a desenvolver sua base de percepção corporal para futuras propostas de experimentação de movimento através da dança.

Shawn ressalta que o conhecimento de tensão e relaxamento desenvolvidos por Steele MacKaye e Genèvieve Stebbins fez com que os movimentos da dança moderna americana fossem feitos de modo fluido, relaxado e sem esforço. Para Shawn a alternância entre as diferentes possibilidades de mobilização muscular, a partir da percepção das nuances entre tensão e o relaxamento do corpo "liberou a dança americana do século XX da monótona tensão constante, que era habitual no método do balé do século XIX" (SHAWN, 1963, p. 63, tradução nossa). A tensão muscular ressaltada por Shawn na observação da técnica do balé, pode ser aprofundada em um excerto da obra "Every Little Movement", quando o artista americano critica:
Durante a última metade do século XIX, na França o balé estava em seu declínio mais profundo - com os baila- rinos preocupando-se com a técnica, de modo a se posicionar e se crista- lizar em um vocabulário de passos, endurecidos pelas posições de braços e restritos à rigidez do dorso, quando braços e pernas moviam-se sem vida como um boneco articulado. (Shawn, 1963 , p. 60 , tradução nossa)

\footnotetext{
do século XX. Das salas de aula da escola DenishawnSchool sairiam nomes como Martha Graham, Dóris Humphrey, Charles Weidman e, segundo a artista e pesquisadora brasileira Holly Cavrell (2015), tais artistas seriam alguns dos responsáveis pela chamada segunda geração da dança moderna americana.
} 
Em busca de diferentes habilidades do corpo, Ted Shawn reflete que o conhecimento de Stebbins e MacKaye sobre tensão e relaxamento ampliariam as capacidades expressivas do tronco de um bailarino, fato constatado quando Shawn começou a experimentar novas possibilidades de movimento. Apresentamos a seguir outro trecho da obra de Shawn, quando o artista americano reflete sobre o uso do dorso dentro da dança moderna americana, em contraponto com a técnica do balé:

Uma das diferenças fundamentais é o reconhecimento do dorso como recurso e instrumento principal de todo expressão emocional autêntica e é igualmente importante o uso das sucessões, começando pelo torso e se dirigindo para fora e para baixo através do corpo como um todo. Isto, obviamente, não seria possível se o torso fosse um elemento do corpo que se mantivesse rígido e fixo na tradição do balé, mas ele deveria tornar-se a mais expressiva e sensível parte do corpo. (Shawn, 1963, p. 61, tradução nossa)

Movimentos que iniciam no dorso e amplia-se em direção às extremidades Shawn utiliza em de seus estudos, sendo um dos princípios de movimento de François Delsarte, que o artista francês nomeia como sucessão. Para Shawn (1963):

A sucessão é definida como qualquer movimento que atravessa o corpo inteiro, ou uma parte dele, que move cada músculo, osso e articulação [...] como um movimento fluido de uma onda. Esta é a maior ordem de movimento para expressão da emoção - e a introdução desta descoberta de Delsarte na dança foi uma das forças principais que direcionaram a dança nomeada como Moderna Americana (Shawn, 1963, p. 34-35, tradução nos$\mathrm{sa)}$

Atravessando o corpo em movimentos flu- ídos de uma onda, as sucessões embaladas pelas nuances musculares propostas por tensões e relaxamentosampliam os desequilíbrios do corpo e nutrem a criação artística de Ted Shawn. Gostaria de exemplicar com fotos da coreografia "Gnossienne", criação desenvolvida no ano de 1919 a partir uma aula ministrada por Ted Shawn, cujo mote de pesquisa seria baseado em desequilíbrio e arcos corporais:

Figura 3: Dois momentos da coreografia Gnossienne (1919), criado e interpretado por Ted Shawn. DenishawnCollection.

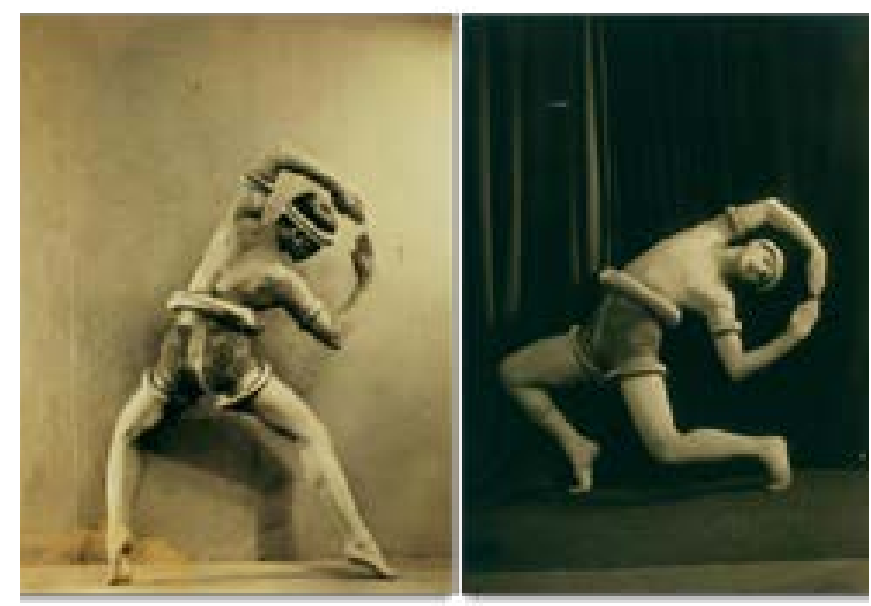

Fonte: Witzel, 1919.

Ao observarmos as fotos de Ted Shawn em "Gnossienne" é possível perceber o estudo de tensão e relaxamento do corpo, quando Shawn (1963) propõe o isolamento de cada pequena porção da coluna vertebral, pois para o artista "cada vértebra pode ser movida separadamente de modo consciente e não haverá rigidez em nenhum lugar da coluna vertebral que obstrua o fluxo de uma sucessão pura" (SHAWN, 1963, p. 61, tradução nossa). Para compreender a delicadeza e complexidade da coluna humana, apresentamosa seguir três desenhos à lápis desenvovidos ao longo da pes-

\footnotetext{
7 As fotografias da coreografia "Gnossienne" apresentadas neste artigo integram o acervo eletrônico da DenishawnCollection. Tais imagens foram digitalizadas em 2013 e disponibilizadas pela Jerome Robbins Dance Division, da New York Public Library for the Performing Arts.
} 
quisa e apresentados em sobreposição:

Figura 4: Coluna vertebral. Ao centro, desenho à lápis de vértebras torácicas e cervicais em conjunto com osso occipital. Nas extremidades, a quinta vértebra lombar em dois ângulos diferentes.

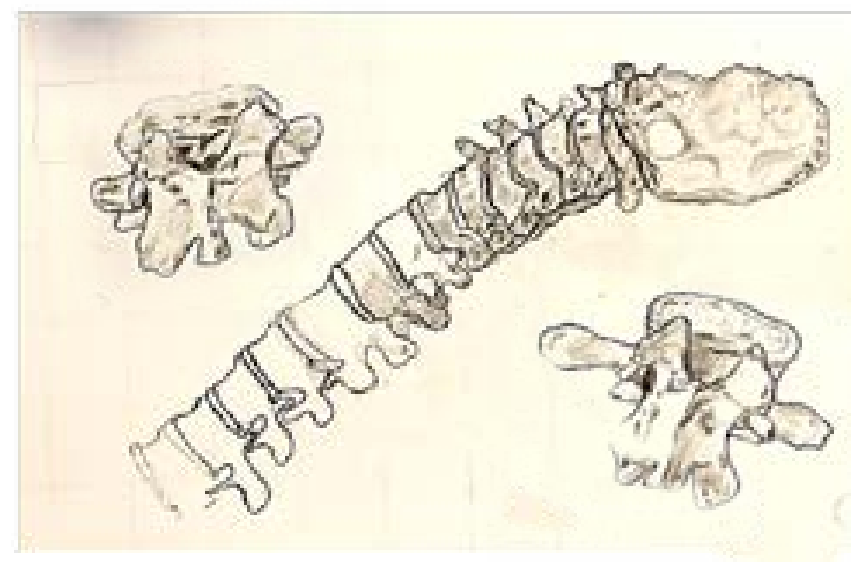

Fonte: Robson Lourenço (agosto/setembro 2014)

Em meio as reflexões entre morte e vida de François Delsarte nos ambientes de dissecação das primeiras décadas do século XIX, que levaram o artista a desenvolver um sistema de estudo de movimento a partir do que ele entendia do movimento excêntrico ao concêntrico, este artigo apresenta um eventual caminho de como os conhecimentos anatômicos atravessaram um oceano e atingiram o movimento da dança. Através da análise de trechos de cartas de Steele MacKaye e das obras Geneviève Stebbins, apresentou a hipótese de que os estudos de tensão e relaxamento propostos por MacKaye e Stebbins são atualizações e desenvolvimentos propostos por ambos e que reverberariam nos estudos de movimento do artista americano Ted Shawn.

As conexões que em um primeiro momento são tão distantes entre os princípios da dança desenvolvidos por Ted Shawn e o estudo do

8 Como já citado na introdução deste artigo, estas reflexões são decorrentes de uma parcela da pesquisa de doutorado desenvolvida entre 2013 e 2017 na UNICAMP e como uma das etapas de investigação, propôs-se a aprendizagem de desenho de observação dos ossos do corpo humano. gesto no canto ou na declamação realizados por François Delsarte encontram-se nos saberes anatômicos de Delsarte, em uma rede de entrelaçamentos de conhecimento sobre o corpo, que atravessa a passagem do século XIX para o século XX. A distância temporal e a relação entre ambos os artistas foram apresentadas a partir da metáfora da pesquisadora francesa Dominique Dupuy (2012), ao afirmar que as conexões entre Delsarte e Shawn poderiam ser definidas a partir da imagem de um lenço, pois este pedaço de tecido, quando:

esticado e passado define distâncias e proximidades fixas: amassado, ele faz com que se aproxime pontos distantes que se avizinham entre si. No tecido liso, Delsarte está de um lado, Ted Shawn de outro e ambos distantes de nós. No lenço amarrotado, Ted Shawn aproxima-se de nós, e traz Delsarte em seu rastro. (Dupuyin Porte, 2012, p. VIII, tradução nossa)

De um lado do tecido Ted Shawn, do outro François Delsarte. Entre a rugosidades reveladas na aproximação dos saberes de Shawn e Delsarte, os vestígios de Steele MacKaye e Geneviève Stebbins abrem espaços entre as frestas articulares e distensionam os feixes musculares para que o corpo da dança moderna crie arcos e mova-se em pêndulos, criando possibilidades para a coluna vertebral experimentar diferentes caminhos de movimento do corpo nas primeiras décadas do século XX.

Referências

CAVRELL, Holly Elizabeth. Dando corpo à História. Curitiba: Prisma, 2015. 
DELAUMOSNE, L'Abbé. The complete work ofL'AbbéDelaumosne. In: Delaumonsne, L'Abbé / Arnaud, Angélique et al. Delsarte System of Oratory. Nova lorque: Edgar S. Werner. 1893. Endereço eletrônico https://archive.org/stream/delsartesystemof00delarich\#page/n5/mode/2up. Acesso em 01.10.2016, às 10h21 min.

DUPUY, Dominique. La mémoire longue ou les cicatrices de la foudre (Préface). In : PORTE, Alain. In : François Delsarte, Une Anthologie. Paris: Ressouvenances, 2012.

FOUCAULT, Michel. O nascimento da clínica. $7^{\mathrm{a}}$ ed. - Rio de Janeiro: Forense Universitária, 2011.

PORTE, Alain. François Delsarte : Une anthologie. Paris: Ressouvenances, 2012.

RUYTER, Nancy Lee Chalfa. The Cultivation of Body and Mind in Nineteenth-Century American Delsartism. Westport: Greenwood Press, 1999.

SHAWN, Ted. Every Little Movement: a book about François Delsarte. Nova lorque: Dance Horizons, 1963.

STEBBINS, Geneviève. Delsarte: System of Expression. Nova lorque: Editado por Edgard S. Werner, 1887. Livro digitalizado pela Biblioteca da Universidade de Harvard. Endereço eletrônico disponível em https://archive.org/stream/ delsartesysteme00delsgoog\#page/n3/mode/2up. Acessoem 22.02.2017, às 08h42min.
Dynamic Breathing and

HarmonicGymnastics: A complete system of psychical, aesthetic and physical culture. Nova Iorque: Editado por Edgard S. Werner, 1892. Livro digitalizado pela Biblioteca da Universidade Estadual de Ohio. Endereço eletrônico: https:// archive.org/details/DynamicBreathingAndHarmonicGymnastics. Acesso em 22.02.2017, às 8h51min.

SUQUET, Annie. Introduction et notes. In: SHAWN, Ted. Chacque Petit Mouvement: À propos de François Delsarte. Paris: Edition Complexe et Centre National de La Danse, 2005.

WAILLE, Franck (org.). Trois décennies de recherche européenne sur François Delsarte. Paris: L'Harmattan, 2011.

Recebido: 15/04/2017 Aprovado: 19/06/2017 